\title{
The Phenolic Potential of Wines from French Grape Varieties Cabernet Sauvignon, Merlot and Syrah Cultivated in the Region of Thessaloniki (Northern Greece) and Its Evolution during Aging
}

\author{
Konstantina Stavridou1, Evangelos H. Soufleros ${ }^{1 *}$, Elisavet Bouloumpasi ${ }^{1,2}$, Vagia Dagkli1 \\ ${ }^{1}$ Department of Food Science \& Technology, Faculty of Agronomy, Aristotle University of Thessaloniki, \\ Thessaloniki, Greece \\ ${ }^{2}$ Department of Oenology and Beverage Technology, Eastern Macedonia and Thrace Institute of Technology, \\ Drama, Greece \\ Email: *esoufler@agro.auth.gr
}

Received 12 December 2015; accepted 26 February 2016; published 29 February 2016

Copyright (C) 2016 by authors and Scientific Research Publishing Inc.

This work is licensed under the Creative Commons Attribution International License (CC BY). http://creativecommons.org/licenses/by/4.0/

(c) (i) Open Access

\begin{abstract}
The aim of this work is mainly to determine the effect of the pedoclimatic conditions ("terroir") on the phenolic composition of wine originated from three French red grape varieties Cabernet Sauvignon, Merlot and Syrah, cultivated in the region of Thessaloniki (Northern Greece); simultaneously a study of its evolution during aging in a stainless steel tank, in oak barrels of different origin and in bottles is conducted. Additionally, in this work, we try to compare the evolution of phenolic composition of wines during aging in French medium toast oak barrel and in American heavy toast oak barrel. For this reason, 20 red wine samples originated from this area were analyzed. The color markers were measured by UV-spectrometry, while the phenolic acids and catechin content of the wine samples and their evolution during aging were determine by UVis-High performance liquid chromatography. Significant differences detected among the three grape varieties regarding color parameters, total anthocyanins and some phenolic acids. The increase of the extraction time during vinification affected the amounts of phenolic acids, catechin, total phenolic index (TPI) and tannin content. Gallic acid and catechin were the most abundant phenolic compounds and their amounts, as well as the concentrations of several phenolic acids were significantly affected during the storage period. Finally, the phenolic composition and the amounts of phenolic acids did not appear to be affected by the origin of oak barrels.
\end{abstract}

${ }^{*}$ Corresponding author.

How to cite this paper: Stavridou, K., Soufleros, E.H., Bouloumpasi, E. and Dagkli, V. (2016) The Phenolic Potential of Wines from French Grape Varieties Cabernet Sauvignon, Merlot and Syrah Cultivated in the Region of Thessaloniki (Northern Greece) and Its Evolution during Aging. Food and Nutrition Sciences, 7, 122-137. http://dx.doi.org/10.4236/fns.2016.72014 


\section{Keywords}

\section{Phenolics, Wine, Aging, French, Varieties}

\section{Introduction}

Studies have shown that the wine phenolic compounds originate mainly from grape extraction during vinification [1] and to a less extent from the wood barrel during maturation or even from yeast metabolism [2] [3] or other microbial sources [4] [5].

It is well known that phenolic compounds are important ingredients of wine and affect several sensory attributes, such as color and astringency [6] [7]. With regard to the influence of phenolic compounds upon wine color, it has been shown that anthocyanins have the stronger effect on the color of young red wines. The concentration of anthocyanins in young red wines ranges between 200 and $500 \mathrm{mg} / \mathrm{L}$, while decreases to 10 to $20 \mathrm{mg} / \mathrm{L}$ during aging [7]. Red wines contain 1500 to $2500 \mathrm{mg} / \mathrm{L}$ of total phenolic compounds [8]. In general, the color of aged red wines, as well as the chemical and sensory profile results from different combinations of the phenolic compounds [9]-[12].

On the other hand, the development of the astringent taste of red wines is due to the concentrated tannins (catechins), which are very important for the long term stabilization of color [13]-[15]. The astringent taste of red wines results from the reaction of saliva proteins (proline rich) with the wine tannins [16].

Antioxidant and antibacterial activity of phenolics has been well established [7]. Flavonoids act as antioxidants and protect plant DNA damage from ultraviolet irradiation. Regarding human health, it is shown that polyphenols protect from cardiovascular diseases. Polyphenols of wines are more biologically available because they exist in a diluted form whereas, in plants, they are either polymerized or insoluble or even strongly bound to other matrices. Moderate wine consumption is associated with decreased cardiovascular diseases even in nations that are well known to follow a high fat consumption diet (French paradox) [17]-[19]. On the other hand, moderate wine consumption is shown to reduce the incidents of senile dementia and Alzheimer disease [20].

Phenolic acids present antibiotic and antiseptic attributes thus are used for food preservation. It is likely that these acids play some role in the microbiological stability of wine, mainly towards bacteria. Those phenolic acids that posses two phenolic hydroxyls $(-\mathrm{OH})$ in ortho-position, such as gallic acid, have the attribute to easily oxidise in quinones, affecting the color of white wines [7]. One of the most important phenolic acids is p-coumaric acid, provided that it is an important metabolite in the formation of phenylalanine lyase, an enzyme that is involved in the formation of flavonoids and stilbenes. It has been found that coumaric acid concentrations increase during stress periods of vine [21]. Furthermore, hydroxycinnamic acids, where p-coumaric acid belongs, form complexes with anthocyanins (pyranoanthocyanins), which contribute to the color stabilization of wine during aging [9] [22].

The purpose of this study is to assess and compare several color markers and phenolic acid concentrations of wine made from different grape varieties, as well as wines vinified with different techniques or aged under diverse conditions.

\section{Materials and Methods}

\subsection{Wine Samples and Terroir}

In the present work 20 wine samples were studied (Table 1). The wines were produced from the French grape varieties Cabernet Sauvignon, Merlot and Syrah, cultivated in the region of Thessaloniki (Northern Greece) and more precisely on the slopes of village Trilofos (vinification at 2004). The soil of this region is classified as CL to a depth of $30 \mathrm{~cm}$, from $30-60 \mathrm{~cm}$ as SCL and from $60-90 \mathrm{~cm}$ as SL. The top soil $(0-30 \mathrm{~cm})$ is characterized as moderate alkaline, moderate in $\mathrm{CaCO}_{3}$ content $(9.2 \%)$ and low in organic matter $(0.41 \%)$ content. The concentrations of $\mathrm{P}, \mathrm{Ca}$ and $\mathrm{Mg}$ are elevated, while the concentrations of $\mathrm{K}, \mathrm{Mn}$ and $\mathrm{Zn}$ very low (Table 2).

All French grape varieties were classically vinified after a six-day extraction period except of the Merlot-c wine, which was extracted for three weeks. All wines were stored initially in a stainless steel tank for 4 months, transferred in barrels for 2 months and finally were bottled in order to study the evolution of color markers during aging. The Merlot-a and Syrah-d wines (Table 1) were stored for 2 months in heavy toast American oak 


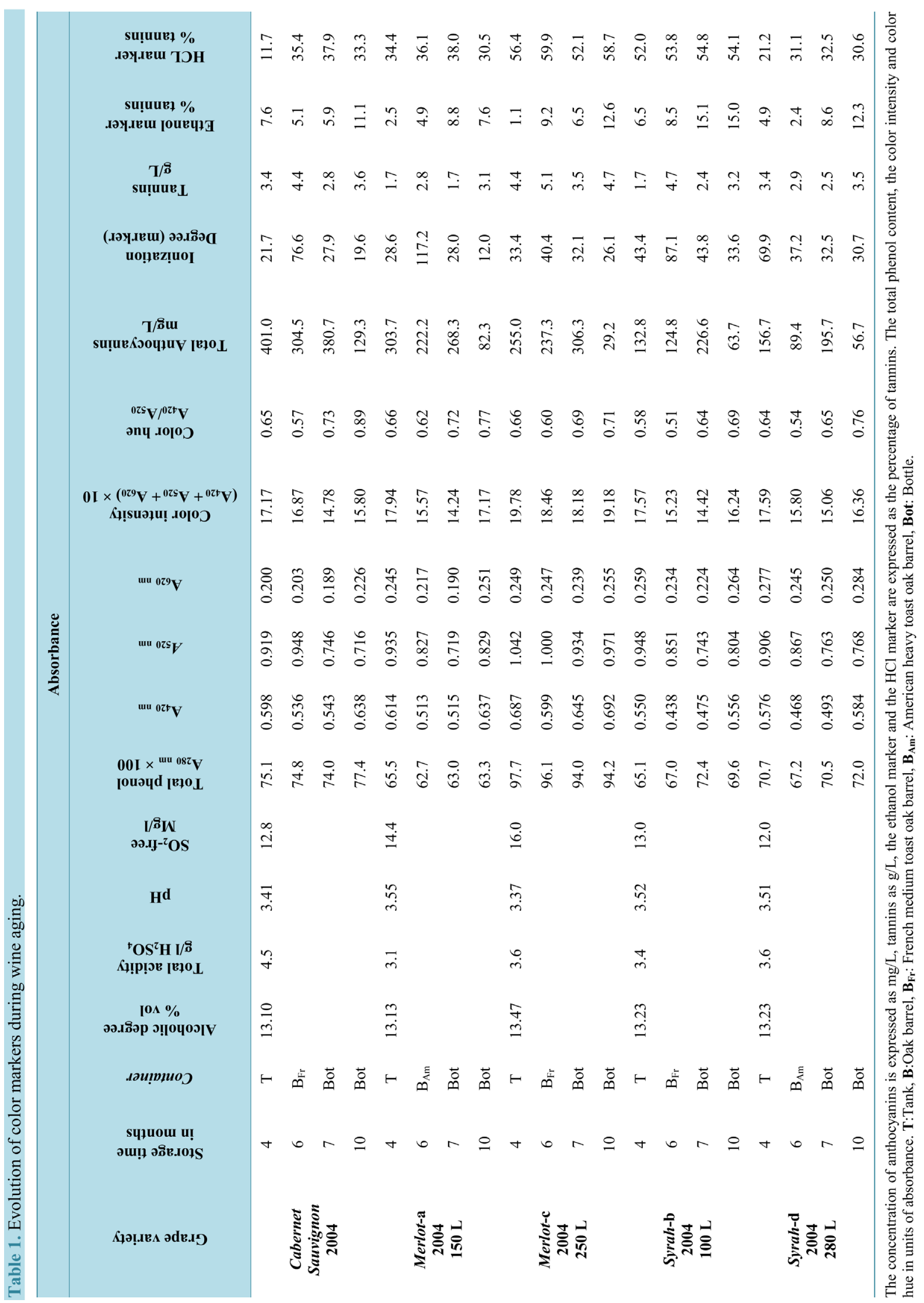




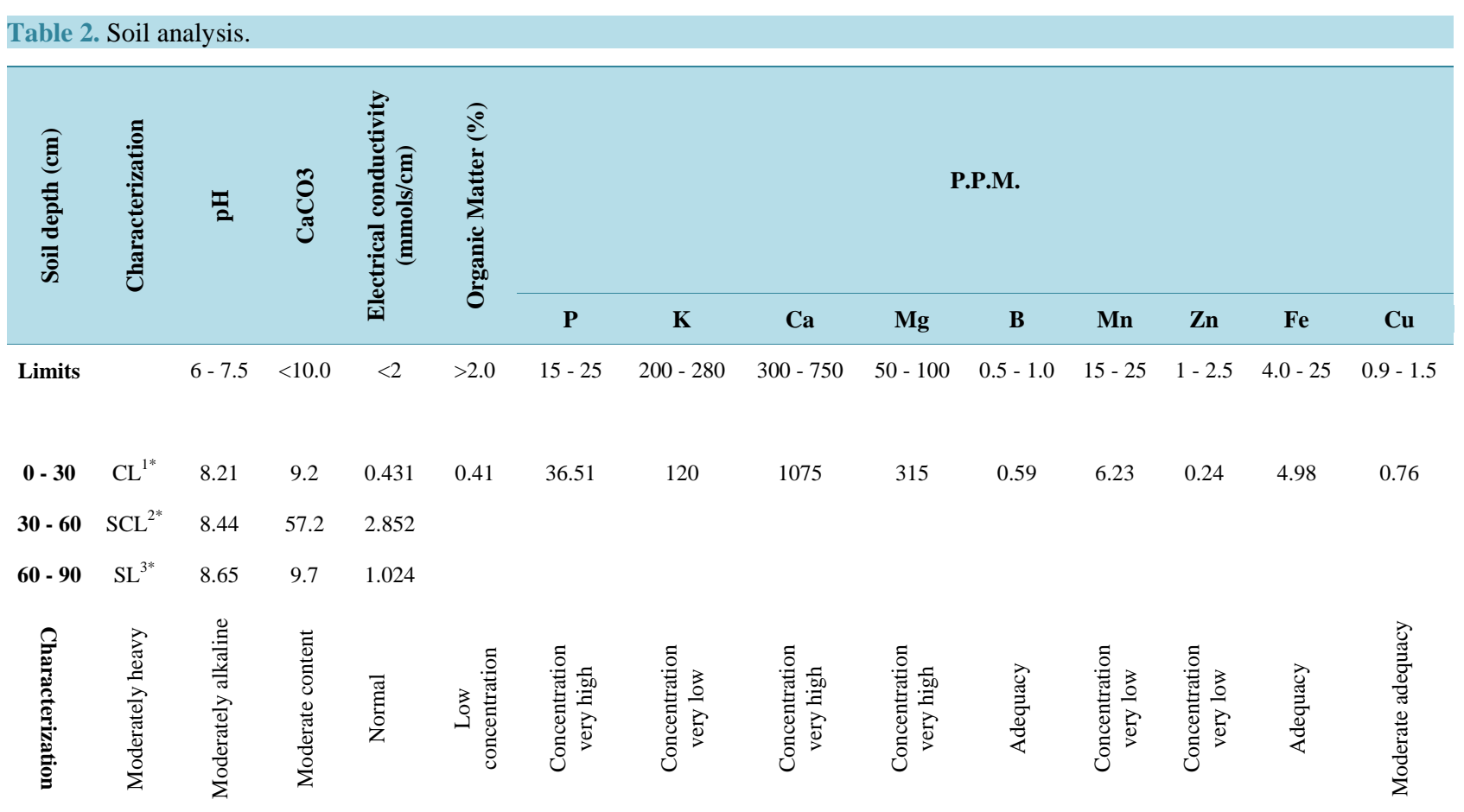

$1^{*}$ : CL: Clay-Loam, 2*: SCL: Sand-Clay-Loam, $3^{*}$ : SL: Sand-Loam.

barrels, while the other wines were stored in medium toast French oak barrels. All the tested wines are demonstrated in Table 1.

\subsection{Determination of Chemical Parameters}

For a better interpretation of the results, alcoholic degree, total acidity, $\mathrm{pH}$ values and free sulfur dioxide of all wines were determined.

The alcoholic degree was determined by the official method by means of densimetry after distillation of wine with a stream of water vapor. The total acidity was determined by titration with $\mathrm{NaOH}$ in presence of Bromothymol blue. For pH measurement a Jenway 3505 pHmeter have been used. The free sulfur dioxide content was determined by the iodiometric titration method. The results are demonstrated in Table 1.

\subsection{Determination of Color Markers}

Several color parameters were measured spectrometrically: total phenolic content, intensity and hue, total anthocyanins, total tannins, the color markers of $\mathrm{HCl}$, ethanol and ionization degree of anthocyanins.

\subsubsection{Total Phenol Index (TPI)}

\section{Materials and procedure}

For the determination of total phenolic index the method of [23] Ribéreau-Gayon et al. (1998) was applied and the high absorbance of aromatic rings of phenolic compounds at $280 \mathrm{~nm}$ was measured. The wine samples were filtered with filters $(1.2 \mu \mathrm{m})$ and diluted with water in a ratio of $1 / 100$. The optical density (A) of the solution was measured at $280 \mathrm{~nm}$ using a UV Spectrometer Hitachi U1100 and quartz cuvettes of one cm light path.

Calculation [23]

$$
T P I=\left(A_{280} \mathrm{~nm}\right) \times 100
$$

\subsubsection{Intensity (I) and Color Hue (T)}

\section{Materials and procedure}

The color of red wines changes from the vivid red of young wines to an orange-red color in old wines, while 
an increase of yellow color compared to red is observed as well. In order to have a complete image the red wine color is essential to measure the absorbance (A) at three wavelengths: at $620 \mathrm{~nm}$ for purple color, at $520 \mathrm{~nm}$ for red and at $420 \mathrm{~nm}$ for yellow color respectively. Initially, the wine samples were filtered using filters of $1.2 \mu \mathrm{m}$ pores. The optical density (A) was measured using a UV-Spectrometer Hitachi 1100 and glass cuvettes of one $\mathrm{mm}$ light path. Distilled water was used as control sample.

Calculation

The color intensity is giving from: $I=\left(A_{420 \mathrm{~nm}}+A_{520 \mathrm{~nm}}+A_{620 \mathrm{~nm}}\right) \times 10$

The color hue is calculated from the equation: $T=A_{420 \mathrm{~nm}} / A_{520 \mathrm{~nm}}$

\subsubsection{Total Anthocyanins}

\section{Materials and procedure}

Anthocyanins tend to react with $\mathrm{SO}_{3} \mathrm{H}^{-}$giving colorless compounds. The degree of wine decolorization after $\mathrm{NaHSO}_{3}$ addition is proportional to the concentration of anthocyanins. For the determination [23], in one ml of wine, one $\mathrm{ml}$ of ethanol containing $0.1 \%(\mathrm{v} / \mathrm{v})$ concentrated $\mathrm{HCl}$ and $20 \mathrm{ml}$ of $\mathrm{HCl} 2 \%(\mathrm{v} / \mathrm{v})$ were added. The mixture was stirred and $10 \mathrm{ml}$ of the mixture were transferred in two test tubes. In the first one, four $\mathrm{ml}$ of distilled water were added and in the second tube four $\mathrm{ml}$ of $\mathrm{NaHSO}_{3} 15 \%(\mathrm{w} / \mathrm{v})$ were added. Twenty min after the addition, the absorbance of the samples was measured at $520 \mathrm{~nm}$, using a UV Spectrometer and glass cuvettes of one cm light path.

\section{Calculation [23]}

$$
\text { Anthocyanins }(\mathrm{mg} / \mathrm{L})=\left(d_{2}-d_{1}\right) \times 885.3
$$

$d_{1}=$ Absorbance of decolorized sample

$d_{2}=$ Absorbance of the sample containing distilled water

\subsubsection{Ionization Degree of Anthocyanins}

\section{Materials and procedure}

$10 \mathrm{ml}$ of centrifuged wine was transferred in a test tube and two $\mathrm{ml}$ of water was added. The absorbance of the sample $\left(d_{1}\right)$ at $520 \mathrm{~nm}$ was measured using a UV Spectrometer Hitachi U1100 and a glass cuvette (1 mm light path). $10 \mathrm{ml}$ of wine were decolorized by adding two $\mathrm{ml}$ of $\mathrm{NaHSO}_{3}$ (density $=1.24$ ). Five minutes after addition the absorbance of the sample $\left(d_{2}\right)$ at $520 \mathrm{~nm}$ was measured using a glass cuvette $(1 \mathrm{~mm})$. One $\mathrm{ml}$ of wine was acidified at $\mathrm{pH}=1.15$ by adding seven $\mathrm{ml}$ of $\mathrm{HCl} 0.1 \mathrm{~N}$. The mixture was diluted with two $\mathrm{ml}$ of water and the absorbance of the sample $\left(d_{3}\right)$ at $520 \mathrm{~nm}$ was measured using a glass cuvette $(1 \mathrm{~cm}$ light path). One ml of wine was acidified at $\mathrm{pH}=1.15$ by adding seven $\mathrm{ml}$ of $\mathrm{HCl} 0.1 \mathrm{~N}$ and the sample was decolorized by adding two $\mathrm{ml}$ of $\mathrm{NaHSO}_{3}$ (density =1.24). Five minutes after addition, the absorbance of the sample $\left(\mathrm{d}_{4}\right)$ at $520 \mathrm{~nm}$ was measured using a glass cuvette $(1 \mathrm{~cm})$.

\section{Calculation}

From the recorded absorbancies the following quantities Dda and Ddg are measured:

Dda $=\left(d_{1}-d_{2}\right) \times(12 / 10)$

$$
\operatorname{Ddg}=\left(d_{3}-d_{4}\right) \times(100 / 95)
$$

Dda: partition of colorized anthocyanins in the optical density at $520 \mathrm{~nm}$ at the $\mathrm{pH}$ of the wine

Ddg: optical density at $520 \mathrm{~nm}$ of the total anthocyanins molecules.

The ionization degree is given from the following equation: DI\% $=(\mathrm{Dda} / \mathrm{Ddg}) \times 100$ and estimates the amount of ionized anthocyanins, which appoint the color of the wine.

\subsubsection{Ethanol Marker}

\section{Materials and procedure}

Ethanol marker estimates the percentage of tannins that form complex with polysaccharides. A part of tannins preexist in the wine originating from the grape while a significant amount comes from the oak barrels during the aging process. The determination of this marker is based on the ability of polysaccharides to precipitate in high concentrations of ethanol and consequently tannins precipitate as well since they are strongly bound. The difference of phenolic content before and after precipitation gives the marker of ethanol.

In a small conical flask, five $\mathrm{ml}$ of wine and $45 \mathrm{ml}$ of ethanol 95\% (v/v) were added. The flask was mixed for 
5 minutes with a magnetic stirrer, covered with parafilm and left at room temperature for 24 hours. After this time, a gelatinous precipitant was formed, which was separated from the mixture during centrifuge at $5000 \mathrm{rpm}$ for $15 \mathrm{~min}$, using a Sigma 3E1 centrifuge. One $\mathrm{ml}$ from the supernatant was diluted with water in a volumetric flask of $10 \mathrm{ml}$. Consequently, the absorbance $d_{1}$ at $280 \mathrm{~nm}$ was measured using a UV Spectrometer Hitachi U1100 and quartz cuvettes ( $1 \mathrm{~cm}$ light path). At the same time a measurement $\left(d_{0}\right)$ of a blank sample was performed as following: One $\mathrm{ml}$ of wine and nine $\mathrm{ml}$ of ethanol $95 \%(\mathrm{v} / \mathrm{v})$ were mixed in a volumetric flask of 100 $\mathrm{ml}$ and diluted with distilled water. The absorbance at $280 \mathrm{~nm}$ was measured instantly (there is no precipitation at the blank sample since the mixing time of wine and ethanol was short).

Calculation

The ethanol marker is calculated from the following equation: M. EtOH $\%=\left[\left(d_{0}-d_{1}\right) / d_{0}\right] \times 100$.

\subsubsection{Marker of $\mathrm{HCl}$}

\section{Materials and procedure}

The HCl marker gives the percentage of polymerized tannins in the wine. Polymerized tannins precipitate in strongly acidic environment. The $\mathrm{HCl}$ marker is calculated from the difference of phenolic content before and after precipitation.

In $10 \mathrm{ml}$ of wine, $15 \mathrm{ml}$ of concentrated $\mathrm{HCl} 12 \mathrm{~N}$ and five $\mathrm{ml}$ of distilled water were added. The mixture was stirred and one $\mathrm{ml}$ of this solution was diluted up to $30 \mathrm{ml}$ with distilled water and the absorbance $\left(d_{0}\right)$ at $280 \mathrm{~nm}$ was measured using a UV Spectrometer Hitachi U1100 and quartz cuvettes of one cm light path. The rest of the solution was left standing for seven hours at room temperature. Afterwards, the solution was centrifuged with a centrifuge Sigma 3E1 and one $\mathrm{ml}$ of the supernatant was diluted up to $30 \mathrm{ml}$ with distilled water and the absorbance (d) at $280 \mathrm{~nm}$ was measured as above.

\section{Calculation}

The HCl marker is calculated from the following equation: M. HCL $\%=\left[\left(d_{0}-d\right) / d_{0}\right] \times 100$.

\subsubsection{Concentration of Tannins}

\section{Materials and procedure}

At acidic environment and under heating, tannins are transformed to anthocyanins. The determination of tannins is based on the colorimetric determination of the formed anthocyanins. One $\mathrm{ml}$ of wine sample was diluted 50 times with distilled water in a volumetric flask of $50 \mathrm{ml}$. Four $\mathrm{ml}$ from this solution was transferred in a test tube and four ml were transferred in another test tube with a ground glass neck joint (reflux). Two ml of distilled water and six ml of concentrated $\mathrm{HCl}$ were added in both tubes. The test tube was fitted with a condenser with a ground glass neck joint (reflux) and then, it was placed in a $100^{\circ} \mathrm{C}$ water bath for $45 \mathrm{~min}$. After heating the tube was cooled and one $\mathrm{ml}$ of ethanol $95 \%$ (v/v) was added in both tubes in order to stabilize the color. Finally, after mixing, the optical densities were measured at $550 \mathrm{~nm}$ with a UV Spectrometer Hitachi U1100 and glass cuvettes (1 cm light path).

\section{Calculation}

The percentage of tannins is calculated from the following equation:

$$
\operatorname{Tannins}(\mathrm{g} / \mathrm{L})=\left(d_{2}-d_{1}\right) \times 19.35
$$

$d_{1}$ : absorbance of the heated tube and $\boldsymbol{d}_{2}$ : absorbance of the non-heated tube

In case, if $\left(d_{2}-d_{1}\right) \leq 0.07$ then the equation becomes: Tannins $(\mathrm{g} / \mathrm{L})=\left(d_{2}-d_{1}\right) \times 20.83$.

\subsubsection{Qualitative and Quantitative Determination of Phenolic Acids and Catechin of Wine by HPLC} Chromatographic analysis was performed using a Marathon IV liquid chromatography apparatus, coupled to a Merck Hitachii L-4250 UV-Vis detector. Chromatograms were monitored at $280 \mathrm{~nm}$ [24]. The analytical column employed was an Adsorbosp here XL C18 $(250 \times 4.6 \mathrm{~mm}$ i.d., $5 \mu \mathrm{m})$ with a precolumn Kromasil C18 5U (7.5 × $4.6 \mathrm{~mm}$ i.d.) (Alltech Associates Inc., Deerfield, IL, USA).

Perchloric acid $0.6 \%$ v/v (70\% - 72\%) in water and Methanol 100\% were used as mobile phases.

The chromatography conditions used were a modification of a program suggested in the literature [24], in order to achieve the best separation of components examined (Table 3).

The identification phenolic acids and catechin was based on the comparison of the retention time of the compounds in the wine samples and the standard solution. The integration of peak areas, which correspond to the 
Table 3. Gradient elution program and column clean up protocol.

\begin{tabular}{cccc}
\hline Time (min) & Solvent A (\% v/v) & Solvent B (\% v/v) & Flow ( $\mathbf{m l} / \mathbf{m i n})$ \\
\hline $\mathbf{0}$ & 100 & 0 & 1 \\
$\mathbf{3 0}$ & 85 & 15 & 1 \\
$\mathbf{4 0}$ & 78 & 22 & 1 \\
$\mathbf{5 0}$ & 0 & 100 & 1 \\
$\mathbf{6 5}$ & 0 & 100 & 1 \\
$\mathbf{7 0}$ & 100 & 0 & 1 \\
\hline
\end{tabular}

determined compounds, was performed using Chrom \& Spec., Chromatography Data System, Version 1.52b (Ambersand International, Inc. 2000) program.

The quantitative determination of phenolic compounds was performed based on calibration curves of reference compounds that resulted from the standard solutions of different concentrations, after a validation of the method as referred in a previous article [25].

\subsection{Statistical Analysis}

Analysis of variance (One-way ANOVA) applied to the results and mean separations were determined by least significant difference (LSD) at $\mathrm{p}<0.05 \%$ and at $\mathrm{p}<0.01 \%$, using SPSS v.10.0 statistical program (SPSS Inc., 2000).

\section{Results \& Discussion}

\subsection{Wine Color Markers and Their Evolution during Aging}

The wine color markers and their evolution during aging in a stainless steel tank, an oak barrel and in a bottle for all wines are demonstrated in Table 1.

\section{Factor 1: grape variety}

The implementation of statistical analysis to the results according to the grape variety revealed significant differences among the three grape varieties regarding color parameters and total anthocyanins (Table 4). More specifically, wines made by Cabernet Sauvignon grapes exhibited the highest content of total anthocyanins among the three varieties, which was significantly higher $(\mathrm{p}<0.01)$ in comparison to Syrah wines. However, Syrah wines exhibited significantly higher values of $A_{620}(p<0.01)$, while wines made of Merlot grapes presented the highest values of $A_{420}(p<0.01)$, which is probably due to their higher potential for oxidation [7] (Table 4).

\section{Factor 2: origin of oak barrel}

Syrah wines were stored in oak barrels of different origin. For Syrah-b wines were used medium toast French oak barrels, while Syrah-d wines were stored in American oak barrels. The aging in barrels of different origin didn't seem to affect significantly the phenolic composition of the wines, with the exception of $\mathrm{HCl}$ marker, where the wines stored in French barrels exhibited significantly higher values, almost double. Other authors reported that medium toast French oak barrels have more tannins and low toasting has a mild effect upon phenol reduction [26]. This theory was confirmed by the obtained results (Table 1).

Syrah-b wines at the end of barrel storage had nearly tripled their tannins amounts (from 1.7 to $4.7 \mathrm{~g} / \mathrm{L}$ on average, respectively), while Syrah-d wines presented values lower than the beginning of the barrel storage (from 3.4 to $2.9 \mathrm{~g} / \mathrm{L}$ on average, respectively). It is reported that heavy toasted American oak barrels have less tannins and the toasting decreases the total phenolic content [27].

\section{Factor 3: length of extraction period}

Merlot-c wine, which was extracted for three weeks, in oppose to six days for Merlot-a wine, had the highest phenolic content among the wines analyzed. More specifically, Merlot-c wine presented significantly higher total phenolic index (TPI) ( $\mathrm{p}<0.001)$, as a result of the longer extraction, as well as higher tannin content. It is already known [28] that concentrated tannins originating from grapes are the most important part of total tannins and their concentration in wine depends, among other factors, and from the extraction period (time). However, 
Table 4. Concentration of catechin and phenolic acids during wine aging (concentration in mg/L of wine).

\begin{tabular}{|c|c|c|c|c|c|c|c|c|c|}
\hline 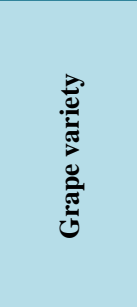 & 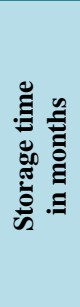 & 壱 & 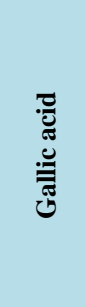 & 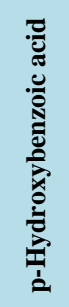 & 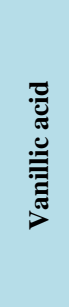 & 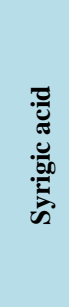 & 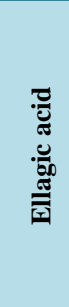 & 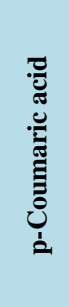 & 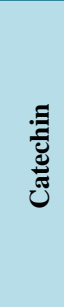 \\
\hline \multirow{4}{*}{$\begin{array}{l}\text { Cabernet } \\
\text { Sauvignon } \\
2004\end{array}$} & 4 & $\mathrm{~T}$ & 48.8 & 3.0 & 15.2 & 1.3 & 0.3 & 13.1 & 6.4 \\
\hline & 6 & $\mathrm{~B}_{\mathrm{Fr}}$ & 59.7 & 6.9 & 16.1 & 2.7 & 2.8 & 8.6 & 24.4 \\
\hline & 7 & Bot & 125.0 & 9.5 & 17.0 & 4.1 & 4.1 & 7.8 & 72.5 \\
\hline & 10 & Bot & 119.8 & 11.8 & 18.3 & 7.6 & 6.2 & 5.4 & 79.8 \\
\hline \multirow{4}{*}{$\begin{array}{c}\text { Merlot-a } \\
2004\end{array}$} & 4 & $\mathrm{~T}$ & 72.7 & 3.1 & 11.5 & 3.5 & 2.8 & 7.9 & 71.1 \\
\hline & 6 & $\mathrm{~B}_{\mathrm{Am}}$ & 80.6 & 3.4 & 12.8 & 4.2 & 6.4 & 7.4 & 52.1 \\
\hline & 7 & Bot & 123.8 & 8.6 & 14.2 & 6.1 & 9.5 & 5.9 & 19.6 \\
\hline & 10 & Bot & 120.1 & 10.9 & 16.0 & 9.6 & 9.7 & 3.3 & 17.0 \\
\hline \multirow{4}{*}{$\begin{array}{c}\text { Merlot-c } \\
2004\end{array}$} & 4 & $\mathrm{~T}$ & 92.4 & 4.8 & 13.2 & 4.6 & 1.3 & 8.4 & 73.6 \\
\hline & 6 & $\mathrm{~B}_{\mathrm{Fr}}$ & 103.5 & 5.0 & 15.3 & 6.8 & 5.7 & 8.0 & 21.1 \\
\hline & 7 & Bot & 120.5 & 7.6 & 16.1 & 9.1 & 9.7 & 4.2 & 14.8 \\
\hline & 10 & Bot & 125.3 & 9.9 & 17.0 & 12.1 & 10.0 & 2.9 & 14.1 \\
\hline \multirow{4}{*}{$\begin{array}{c}\text { Syrah-b } \\
2004\end{array}$} & 4 & $\mathrm{~T}$ & 107.2 & 3.6 & 14.9 & 3.9 & 2.1 & 7.1 & 44.8 \\
\hline & 6 & $\mathrm{~B}_{\mathrm{Fr}}$ & 111.6 & 4.0 & 16.0 & 5.2 & 5.1 & 7.0 & 35.2 \\
\hline & 7 & Bot & 124.5 & 5.9 & 16.4 & 7.3 & 8.7 & 4.7 & 19.7 \\
\hline & 10 & Bot & 120.7 & 8.1 & 18.1 & 8.9 & 8.9 & 4.0 & 16.2 \\
\hline \multirow{4}{*}{$\begin{array}{c}\text { Syrah-d } \\
2004\end{array}$} & 4 & $\mathrm{~T}$ & 108.2 & 3.4 & 13.8 & 4.0 & 4.2 & 6.0 & 32.9 \\
\hline & 6 & $\mathrm{~B}_{\mathrm{Am}}$ & 112.2 & 5.0 & 17.1 & 6.9 & 5.5 & 7.2 & 20.2 \\
\hline & 7 & Bot & 127.1 & 6.2 & 18.4 & 9.0 & 7.6 & 4.3 & 18.4 \\
\hline & 10 & Bot & 123.7 & 8.0 & 18.8 & 10.8 & 8.1 & 3.8 & 15.7 \\
\hline
\end{tabular}

T: Tank, B: Oak barrel, $\mathbf{B}_{\mathrm{Fr}}$ : French medium toast oak barrel, $\mathbf{B}_{\mathrm{Am}}$ : American heavy toast oak barrel, Bot: Bottle.

Merlot-c wine presented lower total anthocyanins and lower ethanol marker.

\section{Factor 4: storage time and type of container}

Wines were stored for 4 months in tank, followed by 2 months in wood barrels, and storage in bottles for 3 months and analyzed by the end of each stage, as well as after the end of the first month of storage in bottles. Results showed that several markers and phenolic acids were significantly affected during the storage period. More specifically:

After two months in wood barrels, wines presented significant differences in the color parameters $\mathrm{A}_{420}$ and hue, in ionization marker, independently by the grape variety. The storage of wines in barrels had as a result the slight decrease of total phenolic index (TPI) of wines, with the exception of Syrah-b wine, where the TPI increased. Similar results were obtained by other researchers [29] [30]. Polymerization reactions of tannins, which occur during aging, are favored in the anaerobic environment of the tank [30] in relation with the condensation reactions of anthocyanins-tannins. Precipitation of these polymerized compounds could lead to a decrease of total phenolics. It has been reported [31] that the total phenolic content was almost stable during aging in a barrel or even increased. This increase was probably due to phenol transportation from the barrel wood to the wine [32].

During barrel storage high amounts of tannins were measured (Figure 1(b)), less anthocyanins (Figure 1(c)), 
(a)

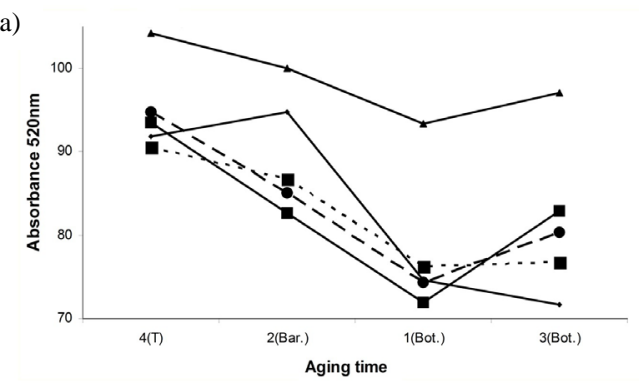

(c)

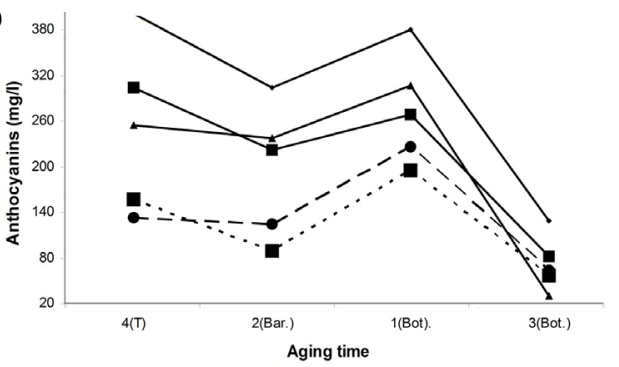

(e)

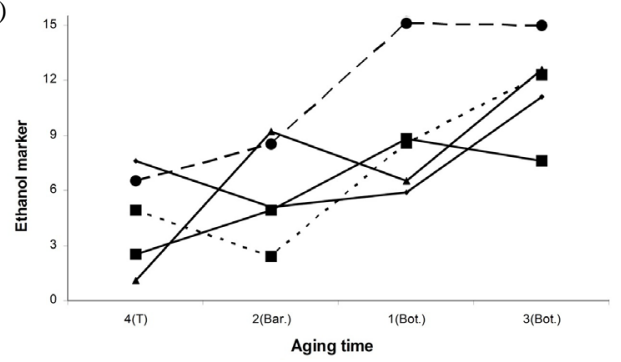

(b)

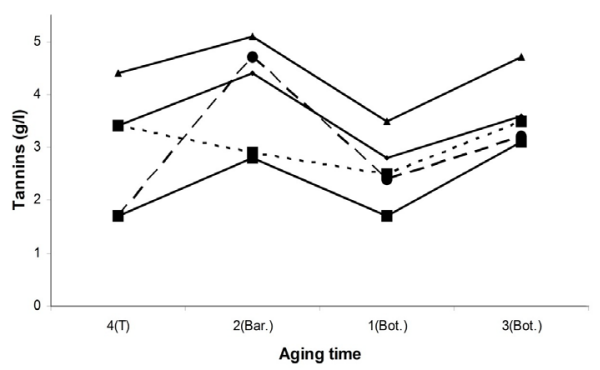

(d)

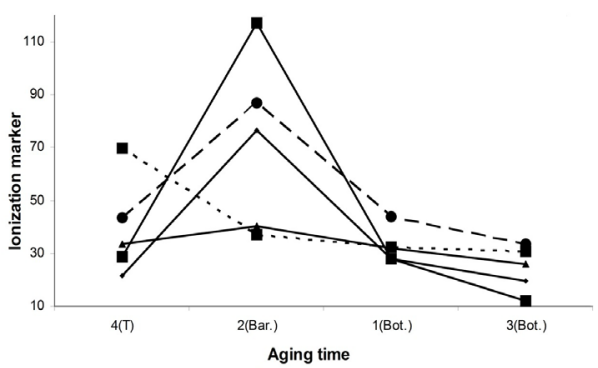

(f)

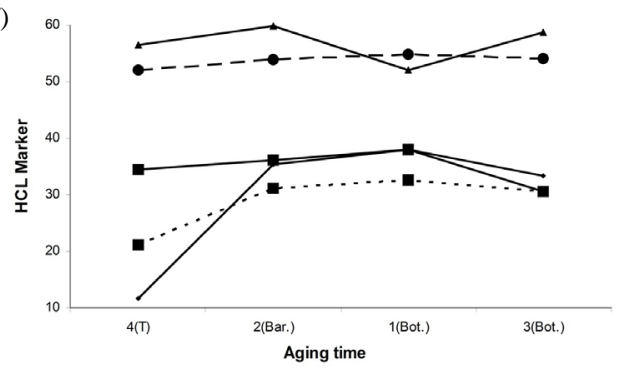

Figure 1. Evolution of phenolic composition and phenolic markers during wine aging.

higher ionization marker (with one exception) (Figure 1(d)) and high $\mathrm{HCl}$ marker (Figure 1(f)). Wines stored in a tank presented stronger color intensity than the corresponding ones stored in a barrel, however the color hue appears significantly stronger in the latter, as a result of the significantly reduced $\mathrm{A}_{420}$ values (Table 1).

It was observed that tannins' concentration was increased in all wines, with the exception of Syrah-d, during wine storage in oak barrels (Figure 1(b)). This fact is due to the tannins extracted from oak barrels [33].

The percentage of free and bound ionized anthocyanins, which exist as flavylium cation, is expressed by the ionization degree [34]. The determination of the ionization degree was based on the intensity of color produced by flavylium cation, which might be due to the formation of compounds resistant to $\mathrm{pH}$ value changes. This fact explains, probably, the increase in the ionization degree observed after the wine was placed in a barrel for two months (Figure 1(d)). This increase was higher twice or three times for the three French varieties, with the exception of Syrah-d wine, where the ionization degree was reduced.

The absorbance at $520 \mathrm{~nm}$ (red color) was reduced in most cases during barrel storage (Table 1, Figure 1(a)), which is in agreement with the findings of other authors [7] [35]. This decrease is attributed to the entry of oxygen in the barrel through the wood pores. In this oxidative environment, condensation reactions take place between anthocyanins and tannins via acetaldehyde, which reacts as a bridge molecule between the reactants [30].

Following the storage in barrels, wines were stored in bottles. Contrary to the storage in barrel, the tannin content of all wines decreased significantly after one month bottle storage $(\mathrm{P}<0.01)$.

The values of absorbance at $420 \mathrm{~nm}$ (yellow color) for the wines produced by the French grape varieties were generally decreased after a few months of aging in an oak barrel and in the first month of aging in bottle (Table 1) and increased significantly, approximately to values similar to the initial ones, after a 3-month aging in a bottle. This increase was due to the oxidation reaction and to reactions between yellow pigments and colorless phenolic compounds during aging. The results are consistent with those reported by other researchers [7] [30] 
[35].

In order to have an objective estimation of wine color, the intensity and hue of color were estimated (Table 1). These two markers are influenced by the total phenolic content, $\mathrm{pH}$ value, redox potential and the concentration of free sulfur dioxide [7]. In our case, $\mathrm{pH}$ values (with the exception of Cabernet Sauvignon) and sulfur dioxide content were similar in almost all samples, and therefore any differences found were not due to these two factors. Results have shown the slight decrease of color intensity during aging, while the color hue in all cases increased, and the increase was statistically significant during aging in bottle. Other authors observed similar results [36] [37]. This reduction of color intensity during aging was the biggest in Cabernet Sauvignon wine (8\%) (from 17.17 to 15.8), while in all other wines of French varieties was less than $8 \%$.

With regard to the anthocyanins, their concentration decreased significantly during aging (Table 1, Table 5 and Figure 1(c)), which is in agreement with previous studies [7] [29]-[31] [35]-[37]. This reduction for wines made of the French varieties was high, varying from 52\% to $88.5 \%$. During aging, anthocyanins participate in polymerization reactions and they form more stable complexes [9] [38]-[41].

As demonstrated in Table 1 and Figure $1(\mathrm{~d})$, the ionization degree decreased significantly $(\mathrm{p}<0.01)$ during wine maturation in the bottle for 3 months. On the contrary, the ethanol marker, which corresponds to the percentage of tannins complexes with polysaccharides presented significant increase for most wines after aging for a few months in a bottle (Figure 1(e)). Polysaccharides originate from the grapes, the yeasts or the wine lees, when the wine matures on them for some time. However, a large proportion comes from wine aging in oak barrel [6]. It is widely known that after fermentation, the extraction of polysaccharides stabilizes the colloid structure of wine [42].

The $\mathrm{HCl}$ marker that expresses the percentage of polymerized tannins increased during aging for Cabernet Sauvignon and Syrah-d wines, while it wasn't significantly affected for the other wine treatments during aging in barrel or bottle (Figure 1(f)).

\subsection{Phenolic Acids and Catechin of Red Wines from French Varieties and Their Evolution during Aging}

The technique of high-performance liquid chromatography was applied for the quantification of phenolic acids and catechin of the wines produced from the French grape varieties Cabernet Sauvignon, Merlot and Syrah which were cultivated in the region of Thessaloniki (Greece), in order to acquire a more specific image for the color and its evolution during wine aging [43]-[46]. Table 6 presents the concentrations of phenolic acids and catechin in $\mathrm{mg} / \mathrm{L}$. Minimum, maximum and average values of these compounds that are reported in literature are given in Table 7 for comparison purposes. Phenolic acids such as, gallic, vanillic and syringic, come from the

Table 5. Concentration of phenolic acids and catechin of wines reported in literature, in $\mathrm{mg} / \mathrm{L}$ (min: minimum value, max: maximum value, m.v.: mean value).

\begin{tabular}{|c|c|c|c|c|c|c|c|c|c|c|c|c|c|c|c|c|c|c|c|c|c|c|}
\hline 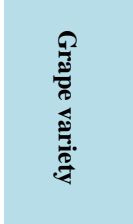 & & $\begin{array}{l}\text { 兰 } \\
\text { ก. } \\
\text { है. }\end{array}$ & & & 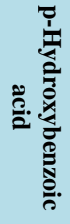 & & & 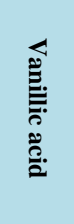 & & & 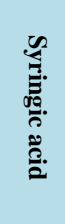 & & & 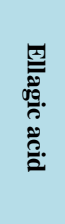 & & & 总. & & & 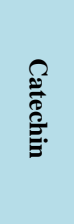 & & 몰 \\
\hline $\begin{array}{c}\text { Cabernet } \\
\text { Sauvignon }\end{array}$ & 5.3 & 158.0 & 38.1 & 1.3 & 16.8 & 9.1 & 1.0 & 33.5 & 8.2 & 1.2 & 13.2 & 5.6 & & & & 1.4 & 25.0 & 6.8 & 6.7 & 97.0 & 40.9 & $\mathrm{a}$ \\
\hline Merlot & 15.3 & 107.8 & 55.5 & & & 13.0 & 2.4 & 9.5 & 4.9 & 1.2 & 9.9 & 4.4 & & & & 0.0 & 10.2 & 3.3 & 14.2 & 89.1 & 55.4 & $\mathrm{~b}$ \\
\hline Syrah & 14.2 & 130.0 & 46.8 & & & & 0.0 & 28.0 & 14.0 & 10.5 & 12.5 & 11.5 & & & & 0.3 & 12.5 & 6.7 & 14.4 & 82.0 & 38.4 & c \\
\hline m.v. & 10.7 & 125.6 & 47.2 & 1.0 & 19.3 & 11.6 & 1.1 & 59.3 & 7.5 & 0.8 & 15.5 & 5.7 & 0.0 & 10.6 & 4.2 & 0.4 & 16.1 & 4.3 & 14.7 & 118.9 & 53.8 & \\
\hline
\end{tabular}

a: [21] [48]-[53] [58] [59]; b: [21] [48] [51] [53]; c: [49] [51]-[54] [58]; d: [2] [3] [18] [19] [21] [48] [49] [51]-[54] [58] [62]. 
grapes and from oak barrels. p-Hydroxybenzoic acid and p-coumaric acid originate exclusively from the grapes, while ellagic acid originates from oak barrels or from the addition of ellagitannins [23].

The gallic acid was present in greater proportion than other phenolic acids in all the wines analyzed (Table 6). Many researchers reported the same regarding the gallic acid content of red wines [18] [21] [47]-[49]. The values of ellagic acid are within the limits reported for other red wines.

\section{Factor 1: grape variety}

The implementation of statistical analysis to the results according to the grape variety revealed significant differences among the three grape varieties regarding some phenolic acids (Table 2). It was reported that their concentrations in red wines depend on the variety rather than aging or geographic origin [18], while other researchers correlate higher concentrations of phenolic acids with origin from hotter regions [21], and lower levels found in rainy regions with low temperatures [51]. The importance of those compounds is attributed to their long duration of remaining "in vivo" after the consumption of the wine [50].

More specifically, wines made by Cabernet Sauvignon grapes contained significantly higher amounts of pcoumaric acid $(\mathrm{p}<0.05)$ and lower amounts of gallic acid $(\mathrm{p}<0.05)$ in comparison to Syrah wines. Wines made of Merlot grapes contained the lowest amounts of vanillic acid $(\mathrm{p}<0.05)$.

Catechin was the second most abundant compound (Table 6). Its concentration generally decreased during aging, independently to the storage container, with the exception of Cabernet Sauvignon wine, where an increase was observed. Our results for the wines made by the three grape varieties are within the limits reported by other researchers [19] [49] [52] (Table 7). Other researchers attribute the differences in catechin content observed for wines of the same variety and different origin to climate conditions [53].

\section{Factor 2: origin of oak barrel}

Table 6. Significant differences $(\mathrm{p}<0.05)$ among wines of different grape varieties, according to their phenolic content.

\begin{tabular}{cc}
\hline Parameters & Significant difference $(\mathrm{p}<0.05)$ \\
A420 & 2 vs. 3 \\
A620 & 1 vs. $2 ; 1$ vs. 3 \\
Total anthocyanins & 1 vs. 3 \\
Gallic acid & 1 vs. 3 \\
Vanillic acid & 2 vs. 3 \\
p-coumaric acid & 1 vs. 3 \\
\hline 1: Cabernet Sauvignon, 2: Merlot, 3: Syrah & \\
\hline
\end{tabular}

Table 7. Significant differences ( $p<0.01$, unless is stated otherwise) among wines during the stages of wine aging, according to their phenolic content.

\begin{tabular}{|c|c|}
\hline $\begin{array}{l}\text { Comparisons between wine treatments } \\
\text { (Xm: storage time in months) }\end{array}$ & Parameters \\
\hline $4 \mathrm{~m}$ vs. $6 \mathrm{~m}$ & A420, color hue, ionization marker, ellagic acid \\
\hline $4 \mathrm{~m}$ vs. $7 \mathrm{~m}$ & $\begin{array}{l}\text { A520, color intensity, ethanol marker, gallic acid, hydroxybenzoic acid, vanillic acid, syringic } \\
\text { acid, ellagic acid, p-coumaric acid }\end{array}$ \\
\hline $4 \mathrm{~m}$ vs. $9 \mathrm{~m}$ & $\begin{array}{l}\text { A520 (p < 0.05), color hue, total anthocyanins, ethanol marker, gallic acid, hydroxybenzoic } \\
\text { acid, vanillic acid, syringic acid, ellagic acid, p-coumaric acid }(\mathrm{p}<0.001)\end{array}$ \\
\hline $6 \mathrm{~m}$ vs. $7 \mathrm{~m}$ & A520, ionization marker, tannins, gallic acid, hydroxybenzoic acid, ellagic acid \\
\hline $6 \mathrm{~m}$ vs. $9 \mathrm{~m}$ & $\begin{array}{l}\text { A420, color hue, total anthocyanins, ionization marker, ethanol marker, gallic acid, } \\
\text { hydroxybenzoic acid, vanillic acid, syringic acid, ellagic acid, p-coumaric acid }\end{array}$ \\
\hline $7 \mathrm{~m}$ vs. $9 \mathrm{~m}$ & A420, A620, total anthocyanins, hydroxybenzoic acid, syringic acid \\
\hline $\begin{array}{l}0 \text { - } 4 \mathrm{~m} \text { : tank storage } \\
4 \text { - } 6 \mathrm{~m} \text { : barrel storage } \\
6 \text { - } 9 \mathrm{~m} \text { : bottle storage }\end{array}$ & \\
\hline
\end{tabular}


It has been reported previously that French oak barrels contain higher amounts of ellagic acid than the American oak barrels [26]. However, our results didn't reveal significant effect of the type of wood barrel on the amounts of phenolic acids measured in the wines after 2 months aging in barrel.

\section{Factor 3: length of extraction period}

Merlot-c wine presented higher amounts in almost all phenolic acids and in catechin, with the exception of ellagic acid. However, significant differences by the application of statistical analysis did not occurred.

\section{Factor 4: storage time and type of container}

Results showed that several phenolic acids were significantly affected during the storage period. More specifically:

After two months in wood barrels wines, independently by variety, wines presented significant differences ( $\mathrm{p}$ $<0.01$ ) in ellagic acid content.

Gallic acid concentration increased significantly $(\mathrm{p}<0.01)$ during aging, independently of the container used for wine storage. Other also observed, as well, that there was an increase in gallic acid in wines coming from grape varieties Cabernet Sauvignon, Cencibel and Syrah after aging for nine months [54]. The gallic acid is a hydrolysis product of wood tannins. During the stay of wine in the barrel, major phenolic compounds of oak, the ellagitannines, which are polymers of gallic acid, are extracted from the wood [55]. The hydrolysis of these compounds contributes to the increase in gallic acid [7].

However, some researchers observed a reduction of gallic acid during aging, which they attributed to oxidation or polymerisation reactions, resulting in conversion of other forms such as quinones or procyanidines and tannins, respectively [37] [56].

In wines made by Syrah and Merlot grapes appeared a decrease in the amount of catechin during wine aging in both barrel and bottle. It is reported that catechin is reduced more during storage in the barrel in comparison to the tank [29] [37], while other researchers observed a decrease of catechin in the beginning, followed by an increase later and attributed the reduction of catechin to its participation in reactions of oxidation and polymerization [54]. As opposed to the other two varieties, Cabernet Sauvignon wines presented very low initial amount of catechin, which elevated significantly during aging (Table 6).

Vanillic acid presented similar levels for all varietal wines. The phenolic acids p-hydroxybenzoic, vanillic, syringic and ellagic increased significantly $(\mathrm{p}<0.01)$ during wine aging, while $\mathrm{p}$-coumaric acid reduced (Table 6, Table 5). Vanillin and syringaldehyde, which are extracted from the oak barrels, act as precursors of vanillic and syringic acids, respectively, contributing to the increase of these acids' concentration in wine [56]. As they are found in the grapes in the form of complex compounds, in which anthocyanins are involved, these acids appear by the decomposition of anthocyanins, during aging, so an increase in the their content is observed [7]. The concentrations of vanillic acid found in the wines analysed at the present study does not exceed the values reported in the literature, while these of syringic acid are close to the limits reportd by other researchers (Table 7).

The p-coumaric acid arises in wine from the hydrolysis of coutaric acid, which takes place slowly during aging [57]. It has been found that the hydrolysis is completed in about three months of aging, and then falls considerably [54]. Other researchers observed that p-coumaric acid reduced during aging, due to its participation in oxidation and polymerization reactions [56]. This reduction may be explained by conversion of p-coumaric acid into volatile phenols by yeasts, in some extent [5]. The results (Table 6, Table 5) show specific decrease in the concentration of p-coumaric acid after wine aging in oak barrels.

\section{Conclusions}

The determination of color markers is essential for red winemaking since they can be used as a tool for monitoring the process. With the aid of color markers, the preservation and aging time of wine can be well predicted thus allowing control to all the necessary treatments. At the present study, the following conclusions are inferred.

Regarding grape variety, significant differences detected among the three grape varieties regarding color parameters, total anthocyanins and some phenolic acids. More specifically, wines made by Cabernet Sauvignon grapes exhibited the highest content of total anthocyanins and also contained significantly higher amounts of p-coumaric acid and lower amounts of gallic acid in comparison to Syrah wines, while wines made of Merlot grapes contained the lowest amounts of vanillic acid.

Regarding the origin of oak barrels, it didn't seem to affect significantly the phenolic composition of the wines and the amounts of phenolic acids, with the exception of $\mathrm{HCl}$ marker, where the wines stored in French 
barrels for 2 months exhibited significantly higher values in comparison to American barrels.

Regarding the duration of extraction, it affected the amounts of phenolic acids and catechin, where the wine extracted for three weeks presented higher amounts of catechin, of almost all phenolic acids except for ellagic acid, and significantly higher total phenolic index (TPI) and tannin content in comparison to wine made by the same variety and extracted for six days.

Regarding the storage in a barrel, it resulted in the reduction of the absorbance at $520 \mathrm{~nm}$ (red color) and color intensity, the increase of the ionization degree of anthocyanins and tannins content (with the exception of Syrah-d wine) and a slight decrease of total phenolic index (TPI), with the exception of Syrah-b wine, where TPI increased. Moreover, independently by variety, wines after aging in a barrel for two months presented significant differences in ellagic acid and p-coumaric acid content, while wines made by Syrah and Merlot grapes showed a decrease in the amount of catechin.

Regarding wine aging, results showed that several phenolic acids were significantly affected during the storage period. Gallic acid concentration increased significantly, irrespective of the container used for wine storage. p-hydroxybenzoic acid, vanillic acid, syringic acid and ellagic acid contents increased significantly during wine aging, while p-coumaric acid reduced. In wines made by Syrah and Merlot grapes appeared a decrease in the amount of catechin during wine aging in bottle.

The participation of tannins in wine clarification stressed to their great significance. Tannin content of all wines decreased significantly after one month bottle storage, while the ionization degree of anthocyanins decreased significantly and the ethanol marker, indicative of the formation of the tannin-polysaccharide complex, presented significant increase during wine maturation in the bottle for 3 months for most wines.

\section{References}

[1] Borbalan, A., Angeles, M., Zoro, L., Guillen, D.A. and Barroso, C.G. (2003) Study of the Polyphenol Content of Red and White Grape Varieties by Liquid Chromatography-Mass Spectometry and Its Relationship to Antioxidant Power. Science Direct-Journal of Chromatography A, 1012, 31-38. http://dx.doi.org/10.1016/S0021-9673(03)01187-7

[2] Burns, J., Gardner, P.T., O’Neil, J., Crawford, S., Morecroft, I., McPhall Donald, B., Lister, C., Matthews, D., MacLean, M.R., Lean Michael, E.J., Duthie Garry, G. and Crozier, A. (2000) Relationship among Antioxidant Activity, Vasolidation Capacity and Phenolic Content of Red Wines. American Chemical Society. Journal of Agricultural and Food Chemistry, 48, 220-230. http://dx.doi.org/10.1021/jf9909757

[3] Burns, J., Gardner, P.T., Matthews, D., Duthie Garry, G., Lean Michael, E.J. and Crozier, A. (2001) Extraction of Phenolics and Changes in Antioxidant Activity of Red Wines during Vinification. Journal of Agricultural and Food Chemistry, 49, 5797-5808. http://dx.doi.org/10.1021/jf010682p

[4] Kennedy, J.A. (2008) Grape and Wine Phenolics: Observations and Recent Findings. Ciencia e Investigación Agrarian, 35, 107-120. http://dx.doi.org/10.4067/s0718-16202008000200001

[5] Silva, L.R., Andrade, P.B., Valentão, P., Seabra, R.M., Trujillo, M.E. and Velázquez, E. (2005) Analysis of Non- Coloured Phenolics in Red Wine: Effect of Dekkera Bruxellensis Yeast. Food Chemistry, 89, 185-189. http://dx.doi.org/10.1016/j.foodchem.2004.02.019

[6] Oberholster, A. (2003) Chemical and Sensory Properties of Grape and Wine Phenolics. Part I. Wynboer-Technical Articles, 1-13.

[7] Soufleros, E. (2015) Enology—Science \& Know-How. Thessaloniki. (In Greek)

[8] Frankel, E.N., Kanner, J., German, J.B., Parks, E. and Kinsella, J.E. (1993) Inhibition of Oxidation of Human Low-Density Lipoprotein by Phenolic Substances in Red Wine. The Lancet, 341, 454-457. http://dx.doi.org/10.1016/0140-6736(93)90206-V

[9] Schwarz, M., Hofmann, G. and Winterhalter, P. (2004) Investigations on Anthocyanins in Wines from Vitis vinifera cv. Pinotage: Factors Influencing the Formation of Pinotin A and Its Correlation with Wine Age. Journal of Agricultural and Food Chemistry, 52, 498-504. http://dx.doi.org/10.1021/jf035034f

[10] Waterhouse, A.L. and Laurie, V.F. (2006) Oxidation of Wine Phenolics: A Critical Evaluation and Hypotheses. American Journal of Enology and Viticulture, 57, 306-313.

[11] Danilewicz, J.C. and Wallbridge, P.J. (2010) Further Studies on the Mechanism of Interaction of Polyphenols, Oxygen, and Sulfite in Wine. American Journal of Enology and Viticulture, 61, 166-175.

[12] Danilewicz, J.C. (2011) Mechanism of Autoxidation of Polyphenols and Participation of Sulfite in Wine: Key Role of Iron. American Journal of Enology and Viticulture, 62, 319-328. http://dx.doi.org/10.5344/ajev.2011.10105

[13] Kennedy, J.A., Hayasaka, Y., Vidal, S., Waters, E.J. and Jones, G.P. (2001) Composition of Grape Skin Proan- tho- 
cyanidins at Different Stages of Berry Development. Journal of Agricultural and Food Chemistry, 49, 5348-5355. http://dx.doi.org/10.1021/jf010758h

[14] Souquet, J.-M., Cheynier, V., Brossaud, F. and Moutounet, M. (1996) Polymeric Proanthocyanidins from Grape Skins. Phytochemistry, 43, 509-512. http://dx.doi.org/10.1016/0031-9422(96)00301-9

[15] Vrhovsek, U., Mattivi, F. and Waterhouse, A.L. (2001) Analysis of Red Wine Phenolics: Comparison of HPLC and Spectrophotometric Methods. Vitis, 40, 87-91.

[16] Edelmann, A. and Lendl, B. (2002) Toward the Optical Tongue: Flow-Through Sensing of Tannin-Protein Interactions Based on FTIR Spectroscopy. Journal of the American Chemical Society, 124, 14741-14747. http://dx.doi.org/10.1021/ja026309v

[17] Amico, V., Napoli, E.M., Renda, A., Ruberto, G., Spatafora, C. and Tringali, C. (2004) Constituents of Grape Pomace from Sicilian Cultivar "Nerello Mascalese". Food Chemistry, 88, 1-13. http://dx.doi.org/10.1016/j.foodchem.2004.02.022

[18] Gambelli, L. and Santaroni, G.P. (2004) Polyphenols Content in Some Italian Red Wines of Different Geographical Origins. Journal of Food Composition and Analysis, 17, 613-618. http://dx.doi.org/10.1016/j.jfca.2003.09.010

[19] Sakkiadi, A.V., Stavrakakis, M.N. and Haroutoumian, S.A. (2001) Direct HPLC Assay of Five Biologically Interesting Phenolic Antioxidants in Varietal Greek Red Wines. Lebensmittel-Wissenschaft \& Technologie, 34, 410-413. http://dx.doi.org/10.1006/fstl.2001.0792

[20] Dartigues, J.F., Berr, C., Helmer, C. and Letenneur, L. (2002) Epidemiologie de la maladie d’Alzheimer. Medicine/ Sciences, 18, 737-743. http://dx.doi.org/10.1051/medsci/20021867737

[21] Kilinc, E. and Kalkan, H. (2003) High-Performance Liquid Chromatographic Determination of Some Phenolic Acids of Turkish Commercial Wines: An Electrochemical Approach. Journal of Wine Research, 14, 17-23. http://dx.doi.org/10.1080/0957126032000114982

[22] Remy, S., Fulcrand, H., Labarbe, B., Cheynier, V. and Moutounet, M. (2000) First Confirmation in Red Wine of Products Resulting from Direct Anthocyanin-Tannin Reactions. Journal of the Science of Food and Agriculture, 80, 745-751. http://dx.doi.org/10.1002/(SICI)1097-0010(20000501)80:6<745::AID-JSFA611>3.0.CO;2-4

[23] Ribéreau-Gayon, P., Glories, Y., Maujean, A. and Dubourdieu, D. (1998) Traité d’oenologie—Tome 2: Chimie du vin. Stabilisation et traitements, Dunod, Editions La Vigne.

[24] Guendez, R., Kallithraka, S., Makris, D. and Kefalas, P. (2005) Determination of Low Molecular Weight Polyphenolic Constituents in Grape (Vitis vinifera sp.) Seed Extracts: Correlation with Antiradical Activity. Food Chemistry, 89, 1-9. http://dx.doi.org/10.1016/j.foodchem.2004.02.010

[25] Soufleros, E., Stavridou, K. and Dagkli, V. (2011) The Effect of Cluster Thinning on Phenolic Maturity of Vitis vinifera cv. Xinomavro Grapes. Journal International des Sciences de la Vigne et du Vin, 45, 1-9.

[26] Canas, S.M., Conceicao, L., Spranger, M.I. and Belchior, A.P. (2000) Influence of Botanical Species and Geographical Origin on the Content of Low Molecular Weight Phenolic Compounds of Woods Used in Portuguese Cooperage. Holzforschunge, 54, 255-261. http://dx.doi.org/10.1515/hf.2000.043

[27] Matricardi, L. and Waterhouse, A.L. (1999) Influence of Toasting Technique on Color and Ellagitannins of Oak Wood in Barrels Making. American Journal of Enology and Viticulture, 50, 519-525.

[28] Kourakou-Dragonas, S. (1998) Themata Oinologias. Trochalia, Athens.

[29] Castellari, M., Sartini, E., Fabiani, A., Arfelli, G. and Amati, A. (2002) Analysis of Wine Phenolics by High-Performance Liquid Chromatography Using a Monolithic Type Column. Journal of Chromatography A, 973, 221-227.

[30] Perez-Prieto, L.J., De La Hera-Orts, M.L., Lopez-Roca, J.M., Frnandez-Fernandez, J.I. and Gomez-Plaza, E. (2003) Oak-Matured Wines: Influence of the Characteristics of the Barrel on Wine Colour and Sensory Characteristics. Journal of the Science of Food and Agriculture, 83, 1445-1450. http://dx.doi.org/10.1002/jsfa.1551

[31] Gómez-Cordovés, C. and Gonzalez-SanJosé, M.L. (1995) Interpretation of Color Variables during the Aging of Red Wines: Relationship with Families of Phenolic Compounds. Journal of Agricultural and Food Chemistry, 43, 557-563. http://dx.doi.org/10.1021/jf00051a001

[32] Jindra, J.A. and Gallender, J.F. (1987) Effect of American and French Oak Barrels on the Phenolic Composition and Sensory Quality of Sevyal Blanc Wine. American Journal of Enology and Viticulture, 38, 133-138.

[33] du Toit, W. (2004) Wood Maturation of Wine (Part II): The Effect of Various Wood Components on the Colour, Flavour and Taste of Wine. Wynboer Technical Articles, WineLand Publications.

[34] Perez-Prieto, L.J., Lopez-Roca, J.M. and Gomez-Plaza, E. (2003) Multivariate Statistical Analysis for the Classification of Oak-Aged Wines Based on Their Chromatic Characteristics. European Food Research and Technology, 217, 512-516. http://dx.doi.org/10.1007/s00217-003-0780-6

[35] del Alamo, M., Bernal, J.L. and Gomez-Cordoves, C. (2000) Behavior of Monosaccharides, Phenolic Compounds, and 
Color of Red Wines Aged in Used Oak Barrels and in the Bottle. Journal of Agricultural and Food Chemistry, 48, 4613-4618. http://dx.doi.org/10.1021/jf9909050

[36] Atanasova, V., Fulcrand, H., Cheynier, V. and Moutounet, M. (2002) Effect of Oxygenation on Polyphenol Changes Occurring in the Course of Wine-Making. Analytica Chimica Acta, 458, 15-27. http://dx.doi.org/10.1016/S0003-2670(01)01617-8

[37] Castellari, M., Matricardi, L., Arfelli, G., Galassi, S. and Amanti, A. (2000) Level of Single Bioactive Phenolics in Red Wine as a Function of the Oxygen Supplied during Storage. Food Chemistry, 69, 61-67. http://dx.doi.org/10.1016/S0308-8146(99)00240-X

[38] Jurd, L. (1969) Review of Polyphenol Condensation Reactions and Their Possible Occurrence in the Aging of Wines. American Journal of Enology and Viticulture, 20, 191-195.

[39] Somers, T.C. (1971) The Polymeric Nature of Wine Pigments. Phytochemistry, 10, 2175-2186. http://dx.doi.org/10.1016/S0031-9422(00)97215-7

[40] Timberlake, C.F. and Bridle, P. (1976) Interactions between Anthocyanins, Phenolic Compounds, and Acetaldehyde and Their Significance in Red Wines. American Journal of Enology and Viticulture, 27, 97-105.

[41] Wang, H., Race, E.J. and Shrikhande, A.J. (2003) Anthocyanin Transformation in Cabernet Sauvignon Wine during Aging. Journal of Agricultural and Food Chemistry, 51, 7989-7994. http://dx.doi.org/10.1021/jf034501q

[42] Klenar, I., Berovic, M. and Wondra, M. (2004) Phenolic Compounds from the Fermentation of Cultivars Cabernet Sauvignon and Merlot from the Slovenian Coastal Region. Food Technology and Biotechnology, 42, 11-17.

[43] Lumuela-Raventos, R.M. and Waterhouse, A.L. (1994) A Direct HPLC Separation of Wine Phenolics. American Journal of Enology and Viticulture, 45, 1-5.

[44] Nagel, C.W. and Wulf, L.W. (1979) Changes in the Antocyanins, Flavonoid and Hydroxycinnamic Acid Esters during Fermentation and Aging of Merlot and Cabernet Sauvignon. American Journal of Enology and Viticulture, 30, 111-116.

[45] Oszmianski, J., Ramos, T. and Bourzeix, M. (1988) Fractionation of Phenolic Compounds in Red Wine. American Journal of Enology and Viticulture, 39, 259-262.

[46] Salagoity-Auguste, M.H. and Bertrand, A. (1984) Wine Phenolics-Analysis of Low Molecular Weight Components by High Performance Liquid Chromatography. Journal of Agricultural and Food Chemistry, 35, 1241-1247. http://dx.doi.org/10.1002/jsfa.2740351116

[47] Arnous, A., Makris, D.P. and Kefalas, P. (2002) Correlation of Pigment and Flavanol Content with Antioxidant Properties in Selected Aged Regional Wines from Greece. Journal of Food Composition and Analysis, 15, 655-665. http://dx.doi.org/10.1006/jfca.2002.1070

[48] Monagas, M., Suarez, R., Gomez-Cordoves, C. and Bartolome, B. (2005) Simultaneous Determination of Nonanthocyanin Phenolic Compounds in Red Wines by HPLC-DAD/ESI-MS. American Journal of Enology and Viticulture, 56, 139-147.

[49] Kallithraka, S., Tsoutsouras, E., Tzourou, E. and Lanaridis, P. (2006) Principal Phenolic Compounds in Greek Red Wines. Food Chemistry, 99, 784-793. http://dx.doi.org/10.1016/j.foodchem.2005.07.059

[50] Simonetti, P., Bardana, C. and Pietta, P. (2001) Plasma Levels of Caffeic Acid and Antioxidant Status after Red Wine Intake. Journal of Agricultural and Food Chemistry, 49, 5964-5968. http://dx.doi.org/10.1021/jf010546k

[51] Nikfardjam, M.S.P., Mark, L., Avar, P., Figler, M. and Ohmacht, R. (2006) Polyphenols, Anthocyanins and transResveratrol in Red Wines from the Hungarian Villany Region. Food Chemistry, 98, 453-462. http://dx.doi.org/10.1016/j.foodchem.2005.06.014

[52] Kallithraka, S., Arvanitoyannis, I.S., Kefalas, P., El-Zajouli, A., Soufleros, E. and Psarra, E. (2001) Instrumental and Sensory Analysis of Greek Wines Implementation of Principal Component Analysis (PCA) for Classification According to Geographical Origin. Food Chemistry, 73, 501-514. http://dx.doi.org/10.1016/S0308-8146(00)00327-7

[53] Goldberg, D.M., Karumanchiri, A., Tsang, E. and Soleas, G.J. (1998) Catechin and Epicathechin Concentrations of Red Wines: Regional and Cultivar-Related Differences. American Journal of Enology and Viticulture, 49, 23-34.

[54] Gutiérrez, I.H., Sanchez-Palomo, L.E. and Espinosa, A.V. (2005) Phenolic Composition and Magnitude of Copigmentation in Young and Shortly Aged Red Wines Made from the Cultivars, Cabernet Sauvignon, Cencibel, and Syrah. Food Chemistry, 92, 269-283. http://dx.doi.org/10.1016/j.foodchem.2004.07.023

[55] Louw, A. (2001) The Occurrence of Bitterness in Wine: An Overview. Wynboer Technical Articles, Wynboer Magazine.

[56] Proestos, C., Bakogiannis, A., Psarianos, K., Koutinas, A., Kanellaki, M. and Komaitis, M. (2005) High Performance Liquid Chromatography Analysis of Phenolic Substances in Greek Wines. Food Control, 16, 319-323. http://dx.doi.org/10.1016/j.foodcont.2004.03.011 
[57] Karagiannis, S., Economou, A. and Lanaridis, P. (2000) Phenolic and Volatile Composition of Wines Made from Vitis vinifera cv. Muscat Lefko from the Island of Samos. Journal of Agricultural and Food Chemistry, 48, 5369-5375. http://dx.doi.org/10.1021/jf000459c

[58] Stockley, C.S. and Hoj, P.B. (2005) Better Wine for Better Health-Fact or Fiction? Australian Journal of Grape and Wine Research, 11, 127-138. http://dx.doi.org/10.1111/j.1755-0238.2005.tb00284.x

[59] Ritchey, J.G. and Waterhouse, A.L. (1999) A Standard Red Wine: Monomeric Phenolic Analysis of Commercial Cabernet Sauvignon Wines. American Journal of Enology and Viticulture, 50, 91-100.

[60] Ibern-Gomez, M., Andres-Lacueva, C., Lamuela-Raventos, R.M. and Waterhouse, A.L. (2002) Rapid HPLC Analysis of Phenolic Compounds in Red Wines. American Journal of Enology and Viticulture, 53, 218-221.

[61] López, M., Martínez Del Valle, C., Orte, C. and Miró, M. (2001) Analysis of Phenolic Constituents of Biological Interest in Red Wines by High-Performance Liquid Chromatography. Journal of Chromatography A, 922, 359-363. http://dx.doi.org/10.1016/S0021-9673(01)00913-X

[62] Soleas, G.J., Dam, J., Carey, M. and Goldberg, D.M. (1997) Toward the Fingerprint of Wines: Cultivar-Related Patterns of Polyphenolic Constituents in Ontario Wines. Journal of Agricultural and Food Chemistry, 45, 3871-3880. http://dx.doi.org/10.1021/jf970183h 